\title{
Differential eyelid conditioning of voluntary form responders'
}

CRAIG W. HICKOK, DAVID A. GRANT AND JANE A. NORTH

UNIVERSITY OF WISCONSIN

\begin{abstract}
Abstraet
Conditioned eyelid responses of 120 men and 120 women Ss were investigated during 60 differential conditioning trials. The CS+ and the CS- were differentially placed lights and the UCS was a corneal "air" puff with an 800 msec. CS-UCS interval. The Ss were classified as conditioners (Cs) or voluntary form responders (Vs) by a time derivative or response slope criterion. The Vs had a higher level of responding to the $\mathrm{CS}_{+}$, a higher level of responding to the CS-, and a greater mean difference score between responses to $\mathrm{CS}+$ and CS- than did the Cs. This was taken to imply that the voluntary response form criterion had behavioral relevance and that the data of Vs should at least be examined separately from those of $\mathrm{Cs}$ in human eyelid conditioning experiments. Further, it appears that the parameters of voluntary form responding merit investigation in their own right.
\end{abstract}

\section{Introduetion}

This investigation compares differential eyelid conditioning of Ss who give primarily voluntary form eyelid responses (Vs) with those giving the usual CR form (Cs). Spence \& Taylor (1951) noted that some Ss in conditioning experiments gave responses of the same form as Ss instructed to blink voluntarily. Because Ss giving a large number of voluntary form responses appeared to behave differently in the conditioned reflex experiment, Spence and his co-workers (e.g., Spence \& Ross, 1959) have felt justified in eliminating the data from this kind of $\mathrm{S}$ from their experiments on eyelid conditioning. In 1959, Spence and Ross reported an objective latency criterion which identified most voluntary form responses when "ready" signals were used, and later Hartman \& Ross (1961) found that an objective measure of response slope (first time derivative) was effective in identifying most voluntary form responses in experiments where no "ready" signal had been given. In the latter case, the latency criterion had proved inadequate.

The problem of the voluntary response form in eyelid conditioning has recently been discussed by Gormezano (1965) and Ross (1965) who mentioned some of the variables affecting the rate of voluntary responding and some of the behavioral differences between Ss giving the voluntary form response and those who do not.

Two papers have reported the behavior of Vs and Cs in differential eyelid conditioning. Hartman \& Grant (1962) found considerable differences between Vs and Cs when the CS-UCS interval was 800 or $1000 \mathrm{msec}$. but very small differences when the interstimulus interval was 400 or $600 \mathrm{msec}$. Similarly, Goodrich, Markowitz,
\& Wall (1963) report essentially no differences in discrimination between the Vs and Cs with a $500 \mathrm{msec}$. CS-UCS interval.

The present data were obtained from 12 groups of 20 Ss each who were all treated alike in the differential conditioning phase but were treated differently in a subsequent discrimination reversal phase. Only the acquisition data are presented in this paper.

\section{Method}

The apparatus used was the same as that described by Hartman \& Grant (1962). The S sat looking into a wooden enclosure $87 \mathrm{~cm}$ wide, $67 \mathrm{~cm}$ high, and $90 \mathrm{~cm}$ deep. The discriminative stimuli were two milk white disks $10 \mathrm{~cm}$ in diameter separated by $55 \mathrm{~cm}$ horizontally and centered vertically inside the back of the enclosure approximately $100 \mathrm{~cm}$ from the $\mathrm{S}$. Illumination in the enclosure was approximately $1 \mathrm{~mL}$. The CS was an $0.8 \mathrm{~mL}$ increase in the brightness of one of the disks for $1 \mathrm{sec}$. The UCS was a $200 \mathrm{msec}$. puff of nitrogen to the right eye at a pressure sufficient to support a $150 \mathrm{~mm}$ column of mercury at the source. The CS-UCS interval was $800 \mathrm{msec}$., the optimum interval for differential conditioning suggested by the results of Hartman \& Grant (1962). The stimulus sequence and the intertrial interval were controlled automatically by a Western Union Tape Transmitter and varied from 15 to $25 \mathrm{sec}$. with a mean of 20 sec. Eyelid movements were recorded from the right eye by means of a lever and microtorque potentiometer. The electric signal was amplified, differentiated, and recorded graphically to permit measurements of latency, amplitude, and rate of eyelid movements.

The Ss were 120 men and 120 women in introductory psychology courses at the University of Wisconsin. They volunteered to serve as experimental Ss and received course credit for participating in the experiment. The Ss were assigned randomly within successive replications of the 12 experimental conditions, except where it was necessary to balance the number of men and women in each group.

During acquisition, all Ss were given 30 trials with the reinforced stimulus and 30 trials with the unreinforced stimulus. The positive and negative stimuli were randomly interspersed with the restriction that each half of the sequence contain 15 reinforced and 15 nonreinforced trials, and that the last trial always be reinforced. For half the Ss the right-hand stimulus was always reinforced (CS+), and for half the Ss the left-hand stimulus was always reinforced. In each instance the other stimulus was never reinforced (CS-). Following attachment of the recording apparatus to the $S$, he was given standard neutral instructions used at the Wisconsin laboratory, telling him that he should neither aid nor inhibit his natural involuntary responses to the stimuli. He was reminded of this following Trial 10.

\section{Results}

All eyelid movements resulting in at least a $1 \mathrm{~mm}$ deflection of the amplitude pen at a latency between 200 and $810 \mathrm{msec}$. following the onset of the CS were considered CRs. The Ss were classified as conditioners (Cs) or voluntary form responders (Vs) by the criterion suggested by Hartman \& Ross (1961). Specifically, any $\mathrm{S}$ who on the first 60 trials gave more than $50 \%$ of his CRs with greater than $35 \%$ of the mean time derivative of his first five reflex blinks to the puff was classified as a V. All other Ss were classified as Cs. In the 12 groups the number of $\mathrm{Cs}$ varied from 5 to 11 , and the 


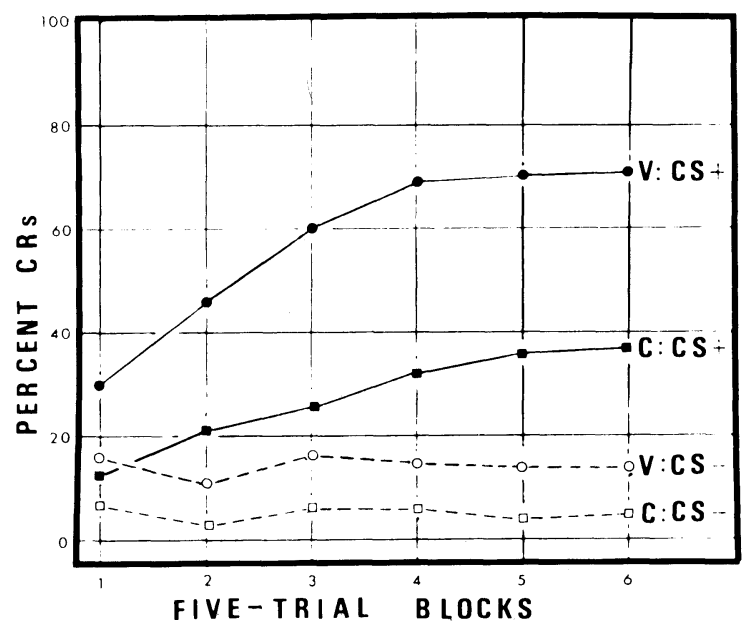

Fig. 1. Acquisition of conditioned discrimination in human Ss, showing voluntary form responses (Vs) and non-voluntary form responses (Cs). Percent CRs are plotted for successive fivetrials with the reinforced $\mathrm{CS}\left(\mathrm{CS}_{+}\right)$and the non-reinforced $\mathrm{CS}(\mathrm{CS}-)$.

number of Vs varied from 9 to 15 , totaling $96 \mathrm{Cs}$ and 144 Vs.

The percent CRs as a function of successive blocks of trials during acquisition are shown in Fig. 1. Per cent CRs are plotted against six successive five-trial blocks with the positive CS and the negative CS, separately for the Vs and Cs. Thus, each data point for the Cs was based on 480 trials, and each data point for the Vs was based on 720 trials.

Figure 1 shows clearly that the per cent response increases over blocks of trials for the reinforced stimuli, the two upper curves, nd essentially remains stable for the non-reinforcad stimuli, the two lower curves. There is a dramutic difference between the Vs and the $\mathrm{Cs}$ in the acquisition of differential eyelid conditioning. The Vs respond at a higher level to CS+ and also to CS- and there is a greater difference between per cent responding to $\mathrm{CS}+$ and $\mathrm{CS}-$ in the case of the Vs as opposed to the Cs. For the last 30 acquisition trials, the Vs and Cs were compared with respect to the total number of responses to $\mathrm{CS}+, \mathrm{F}(1,238)=73.04$; with respert to the mean number of responses to CS-, $F(1,238)=15.91$; and with respect to the number of responses to $\mathrm{CS}+$ minus the number of responses to CS-, $\mathrm{F}(1,238)=39.4$. All Fs were significant at the $\mathrm{p}<.0001$ level. The error mean squares were approximately 22 for total responses to CS+ and for the difference scores and 7 for the responses to CS-. Parenthetically, these scores did not differ among the 12 groups, the largest $F(11,132)=1.03$.

\section{Discussion}

The terminal levels of responding to the positive and to the negative conditioned stimuli were very similar to those obtained by Hartman \& Grant (1962) for the $800 \mathrm{msec}$. CS-UCS interval, although response levels in the present study were all somewhat lower than in the earlier one.

The data show clearly that there is a behavioral difference between Ss giving the voluntary form response and other Ss in the acquisition of conditioned discrimination. The final levels of differences between per cent $\mathrm{CRS}$ to $\mathrm{CS}+$ and to CS- were neither proportional (approximately $70 / 15$ for $\mathrm{Vs}$ and $35 / 5$ for $\mathrm{Cs}$ ) nor equal (55\% difference in Vs and $30 \%$ difference in Cs), so that simple interpretations such as those in terms of Vs being more rapid conditioners than Cs (Gormezano, 1965, p. 67) appear to be ruled out.

Bearing in mind that the classification of an $\mathrm{S}$ as a $\mathrm{V}$ or a $\mathrm{C}$ depended solely upon the criterion of response slope, superior differential conditioning of Vs is of considerable interest per se. Although the response slope criterion can hardly be claimed to be a perfect one, it is clearly relevant to conditioning behavior; Vs do not respond like $\mathrm{Cs}$ in differential conditioning.

Two implications follow: (1) the data of Vs should always be examined separately from those of $\mathrm{Cs}$ in in human conditioning experiments, and (2) the parameters of voluntary form responding (e.g., behavioral laws of Vs as opposed to $\mathrm{Cs}$ and variables affecting or producing voluntary form responding) merit investgation.

\section{References}

Goodrich, K. P., Markowitz, J., \& Wall, A. M. Differential eyeblink conditioning in voluntary and nonvoluntary subjects. Psychol. Rep., 1963, 13, 723-730.

Gormezano, I. Yoked comparisons of classical and instrumental conditioning of the eyelid response; and an Addendum on "voluntary responders." In W. F. Prokasy (Ed.), Classical conditioning New York: Appleton-Century-Crofts, 1965.

Hartman, T. F., \& Grant, D. A. Differential eyelid conditioning as a function of the CS-UCS interval. J. exp. Psychol., 1962, 64, $131-136$.

Hartman, T. F., \& Ross, L. E. An alternative criterion for the elimination of "voluntary" responses in eyelid conditioning. $J$. exp. Psychol., 1961, 61, 334-338.

Ross, L. E. Eyelid conditioning as a tool in psychological research: Some problems and prospects. In W. F. Prokasy (Ed.), Classical conditioning. New York: Appleton-Century-Crofts, 1965.

Spence, K. W., \& Ross, L. E. A methodological study of the form and latency of eyelid responses in conditioning. J.exp. Psychol., $1959,58,376-381$.

Spence, K. W., \& Taylor, J. A. Anxiety and strength of the UCS as determiners of the amount of eyelid conditioning. J. exp. Psychol., 1951, 42, 183-188.

\section{Note}

1. This research was supported in part by a grant from the National

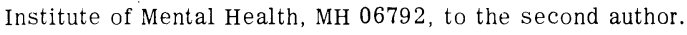

